A R C H I V E

$\mathrm{O} \mathrm{F}$

M E C H A N I C A L

E N G I N E E R I N G

\begin{tabular}{lcr}
\hline VOL. LX & 2013 & Number 4 \\
$10.2478 /$ meceng-2013-0035 & &
\end{tabular}

Key words: control system, telemanipulator, surgical robot, singularity

\author{
ADAM NIEWOLA* ${ }^{*}$ LESZEK PODSĘDKOWSKI*, PIOTR WRÓBLEWSKI*, \\ PIOTR ZAWIASA*, MARCIN ZAWIERUCHA*
}

\title{
SELECTED ASPECTS OF ROBIN HEART ROBOT CONTROL ${ }^{1}$
}

\begin{abstract}
The issues of medical robots have been approached for 12 years in the Institute of Machine Tools and Production Engineering of the Technical University of Lodz. In the last two years, the scope of research related to the miniaturization of surgical tools, automated changing of these tools with the use of a tool depot designed for this purpose, equipping the robot in the sense of touch and developing the software which provides ergonomic and intuitive robot control with the use of all its functions. In the telemanipulator control, strong emphasis is placed on the intuitiveness of control, which is hard to be ensured due to the fact that the robot tool is observed by a laparoscopic camera, whose orientation and position may vary. That is the reason for developing a new algorithm. It copies the increments of the position and orientation measured in relation to the monitor coordinate system onto the robot tool movement and orientation, which are measured in relation to the camera coordinates system. In this algorithm it is necessary to solve inverse kinematics, which has a discontinuity. Avoiding the discontinuity is achieved by mapping the solution with the cosine function. It causes smooth pass through the area of discontinuity in this way avoiding the singularity.
\end{abstract}

\section{Introduction}

In the 1970s, the idea of using robots in medicine appeared. The factor which led to connecting such distant fields as robotics and medicine was an idea of using robots controlled from the Earth to ensure required healthcare for astronauts in space. First cases of using the robot in practice in medicine

${ }^{*}$ Technical University of Lodz, Institute of Machine Tools and Production Engineering, Stefanowskiego 1/15 Street; 90-924 Lódź, Poland; E-mail: adam.niewola@gmail.com; lpodsedk@p.lodz.pl; piotr.wroblewski@p.lodz.pl; piotr.zawiasa@p.lodz.pl; marcin.zawierucha@p.lodz.pl

1 This work was made in grants 2011/01/B/ST7/04011 and 2012/05/N/ST8/02262 from National Science Centre 
date to the 1980s. The first telemanipulators designed to perform laparoscopic surgery were presented in the 1990s.

There are two manipulators in the telemanipulation system for laparoscopic surgery. Surgeon-operator using the first one, which is called master manipulator, performs certain movements, which are then converted and copied to the second manipulator called the slave manipulator, which has a laparoscopic tool mounted at the end of the effector.

Currently, in minimally invasive surgery the most important are three constructions of telemanipulators. One of them - the Zeus robot is not currently produced and its designer - Computer Motion joined the Intuitive Surgical which designed another robot - da Vinci, which is still being produced. The third construction - DLR MiroSurge is in the testing phase [1].

In Poland, the research in the field has also been conducted. In the year 2000, works began to develop a Polish cardiosurgical telemanipulator Robin Heart started. The first version of the arm - Robin Heart 1 (RHI) - was created as a part of the research project led by Professor Zbigniew Religa [3]. The works were funded by the KBN (Committee for Scientific Research) and the FRK (Foundation of Cardiac Surgery Development) in Zabrze and carried at the FRK and the IOiTBM PL(Institute of Machine Tools and Production Engineering at Technical University of Lodz). The arm has a spherical structure with its center point displaced outside the mechanism. During the surgery, the arm is placed in such a way that the center of the sphere can coincide with the opening in the patient's body. The arm mounting system is equipped with three actuated degrees of freedom to provide this function. The arm was designed to be mounted on an independent column, standing next to the surgical table.

In 2007, as a part of an ordered research project, two additional arms were created: RobIn Heart Vision (RHV) [4] which was designed to hold the laparoscopic camera and RobIn Heart 3 (RH3) that comes with interchangeable surgical tools. The kinematics and basic design parameters of these arms were similar to those of RobIn Heart 1. The arms and tools were designed and created at the IOiTBM PŁ. The detail of the design and the test results were presented in [6], and the results of first animal surgeries can be found in [5]. The further research was related to the reduction of collision space of the manipulator [2] and creating the system of feedback force on the tool $[9,10,16]$.

The construction of da Vinci and RobIn Heart robots are similar, both of them having spherical kinematics with the centre of sphere located outside of the mechanism. However, master manipulators and robot control approaches are different for these robots. 
Among the number of requirements which are expected from master manipulators (precision, resolution, stiffness of construction, low inertia, low friction), the requirements for ergonomics of operation appear to be in the foreground. The intuitive robot control is of high importance for the surgeon. Eliminating unintuitive control of traditional laparoscopic tools should be one of the utmost advantage of using surgical robots as compared to conventional surgeries.

There are several approaches to control the robot for laparoscopic surgery. One of them is based on calculating the position and orientation of the master manipulator in its base coordinates system and converting them into the position and orientation of the robot also in its base coordinates system. Another approach assumes the calculation of the position and orientation in the local coordinates systems of the effector of the master manipulator and of the tool of the robot. Both of these approaches do not take into consideration the fact that the laparoscopic tool is located in the body of the patient, and is not observed by the surgeon directly but with the laparoscopic camera whose position and orientation may vary.

Therefore, the intuitive control of such systems is dependent on the current position of the effector and the camera. These approaches do not provide the surgeon with the required ergonomics.

\section{Robin Heart - the design}

After the successful surgical operation in 2009 conducted on a pig by a set of Polish RobIn Heart 1 robots [5], the scientific team of the Institute of Machine Tools and Production Engineering at the Technical University of Lodz decided to focus on the new aspects of the robot's functionality. One of these was a simplified procedure of tool changing. The reason for tackling this problem was the considerable length of time necessary to perform such an action by the RobIn Heart 1 and the $d a$ Vinci robots. In the previous version of RobIn Heart 1 (Fig. 1a, b) (as well as in da Vinci - Fig. 1c and MiroSurge - Fig. 1d) the end effector interchanging procedure was performed by disconnecting whole tool wrist integrated with sleeve connected to the drive unit. The time necessary to change a single tool ranged from 30 to 120 seconds. During such a cycle, the tool had to be pulled out from the patient's body, which was followed by disassembling the tool, putting it away, acquiring a new one, assembling it onto the robot and sliding it back into the patient's body. During a 2-hour surgical operation there could be up to 50 tool changing procedures, therefore it could extend the operation's time by $30-50$ minutes which amounts to $25-40 \%$ of the operation time. The procedure requires an operating assistant to be present and her/his proficiency also 
impacts the tool changing time. This analysis shows that the development of a new set of end effectors would expand capabilities of Polish RobIn Heart robot by an innovative feature that is not present in other constructions, including the $d a$ Vinci robot which remains the only one, performing heart operations at the moment.

The solution led to the development of an end effector interchanging system and an automated end effectors magazine used for tool changing during the operation. Both were implemented to RobIn Heart 3 (Fig. 2 and 3) robot.

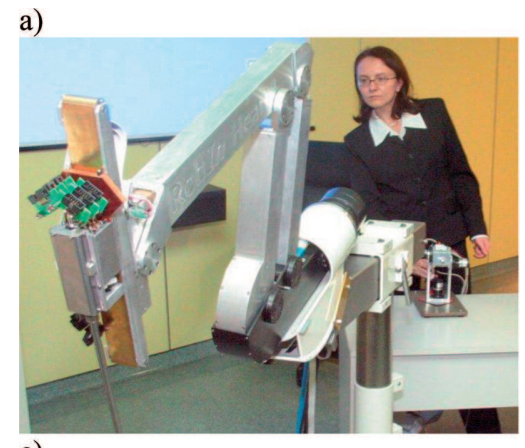

c)

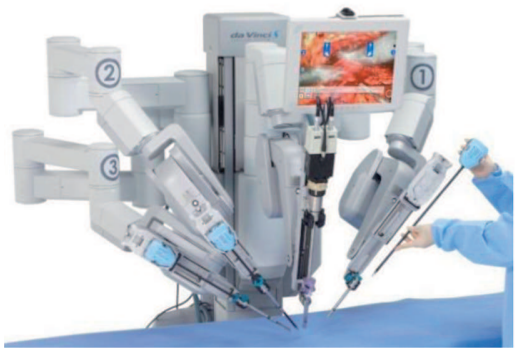

b)

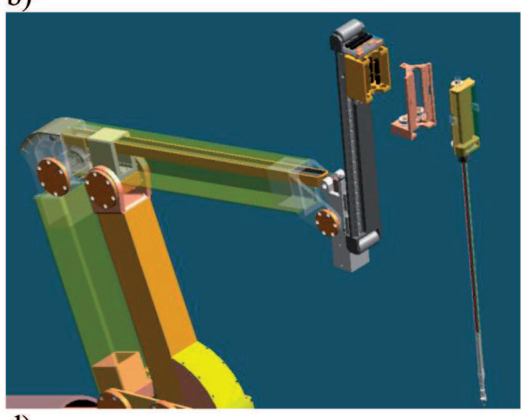

d)

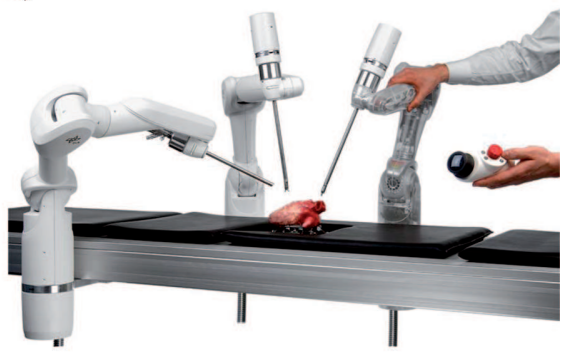

Fig. 1. a) RobIn Heart 1, b) the tool installation method in RobIn Heart 1, c) the tool installation method in da Vinci [17], d) DLR MiroSurge robot (Copyright: DLR) [18]

The innovation implemented to the new tool system is the use of the interchangeable end effectors that are connected right after the last joint of the wrist (Fig. 3). The end effector's propulsion system uses a four-bar linkage which increases the force during the jaws closing [14]. Due to that solution it was possible to create an interchangeable end effectors magazine (Fig. 4) with an automated end effectors interchanging procedure that does not need the whole drive system to be removed.

The main end effectors magazine design assumption was its maximum integration with RobIn Heart 3 robot and the possibility to use at least 5 interchangeable end effectors (Fig. 4). The design presented at Fig. 4 consists 


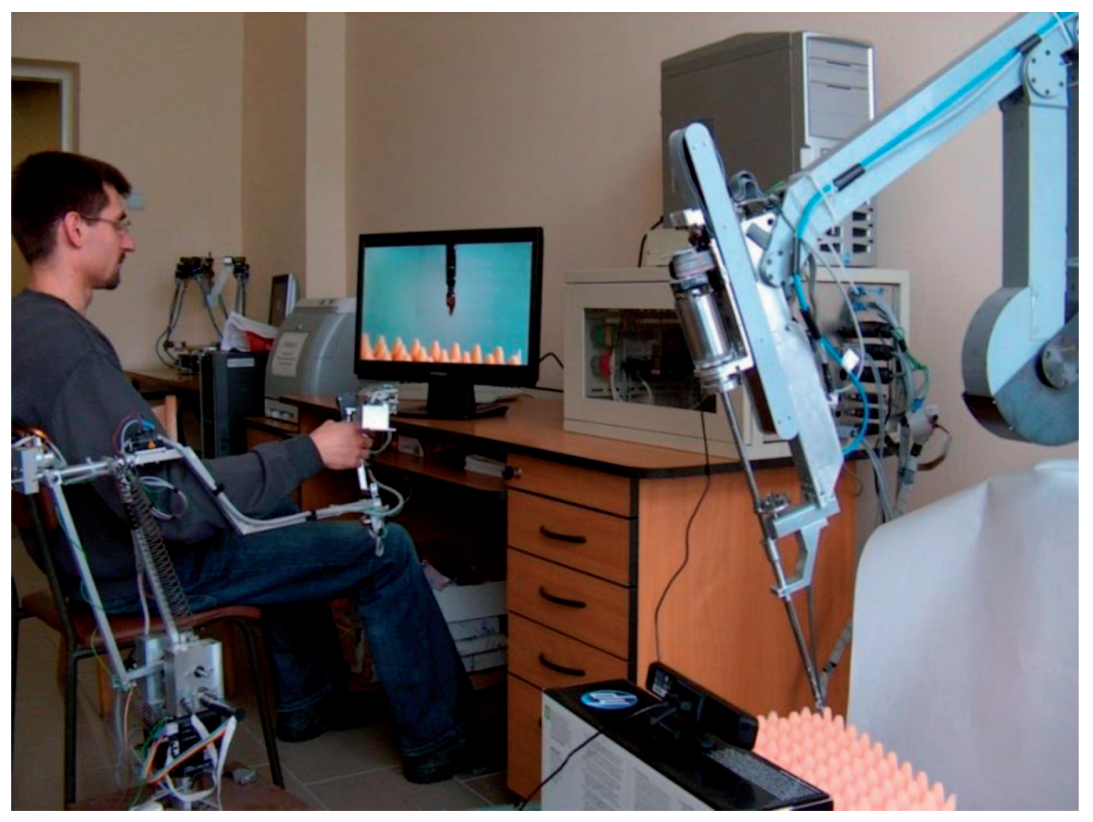

Fig. 2. RobIn Heart 3 - overview

a)

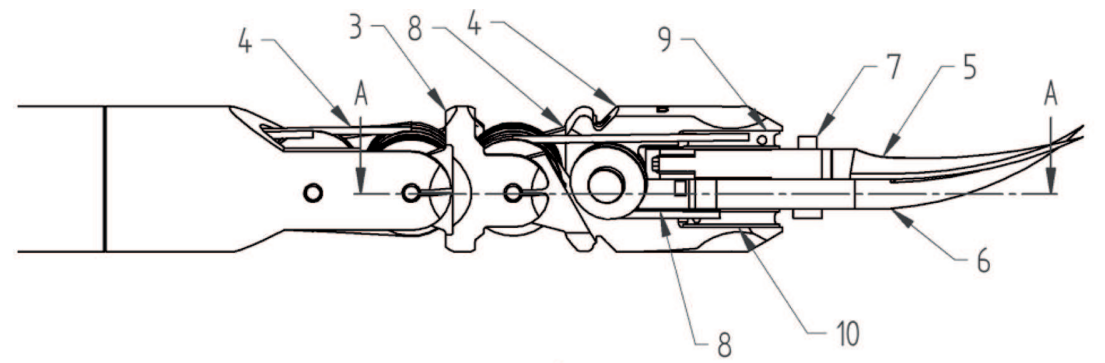

b)

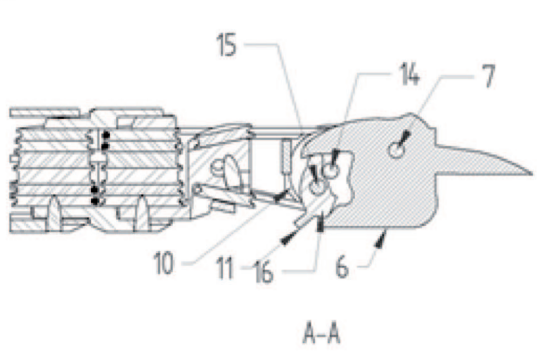

c)

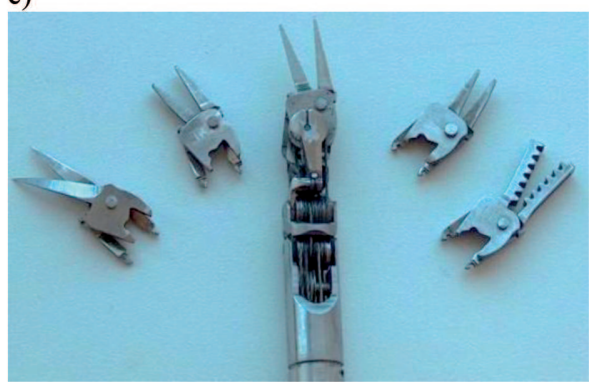

Fig. 3. Design (a, b) and picture (c) of the tool and interchangeable tooltips

of 1 - drive, 2 - magazine port fixed to robot's arm, 3 - tooltips, 4 - tooltips port, 5 - revolving disc, 6 - cannula handle, 7 - tool driving hole. 
Changing the end effectors in the described solution requires the following steps:

1. closing of the jaws (II position on Fig. 5) and removing the tool with an end effector into the position located above the magazine in order to allow it to move freely;

2. placing the magazine in the position with a free socket (II tool position above IV socket position);

3. lowering the tool with an end effector inside the socket (the sloping surfaces of the jaw (1) slide aside the arms of the fixing springs);

4. opening tool jaws with a larger than normal work angle (the angle between normal jaws position and base position ranges from $0^{\circ}$ to $20^{\circ}$, fig.5, I position). The dents (4) becomes uncovered and the clamp spring (3) is placed inside it. Also, the mechanism placed inside the tool's cluster unlocks the movement of the jaw (1) inside the cluster (V position);
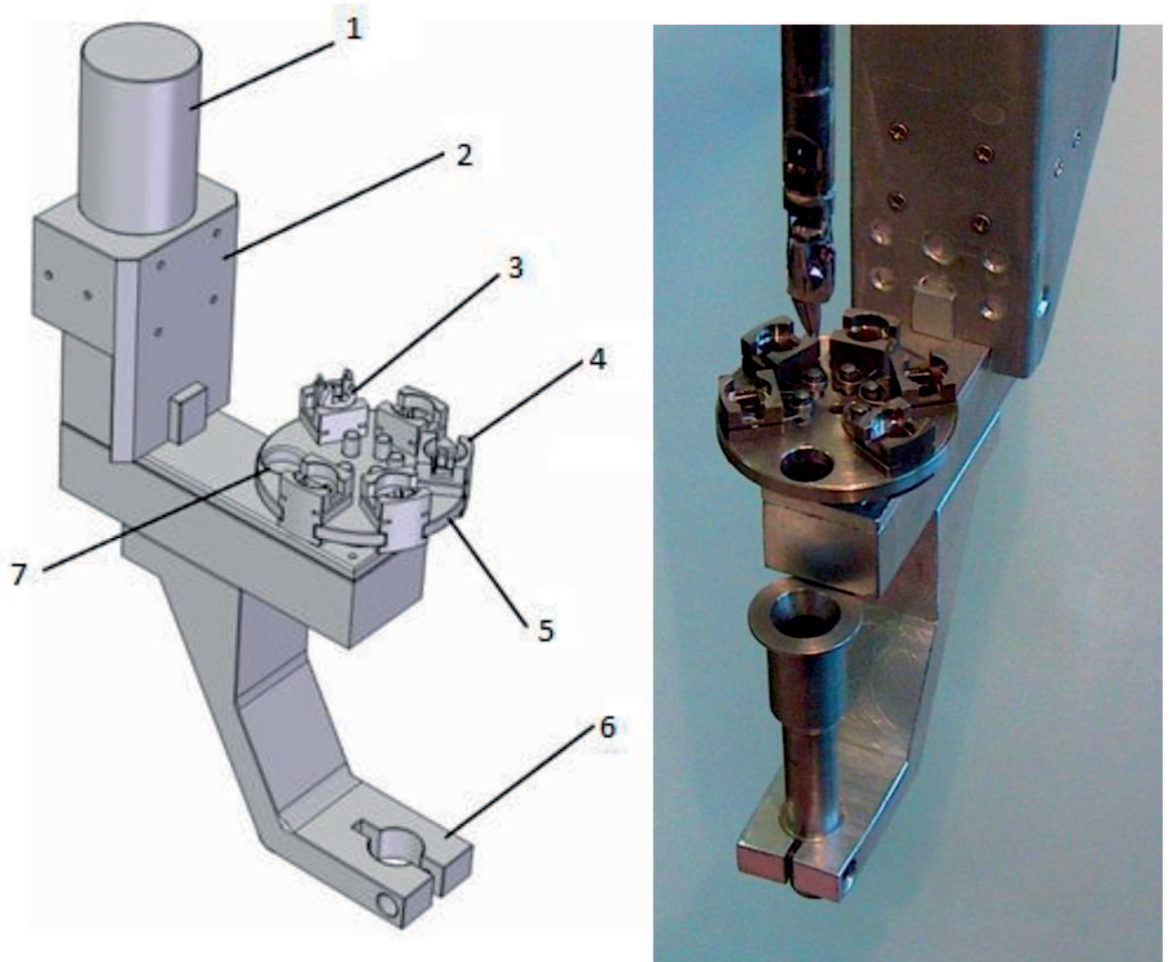

Fig. 4. Interchangeable end effectors magazine elements and the final construction. 1 - drive, 2 body, 3 - tool inside socket, 4 - socket, 5 - magazine disc, 6 - cannula grip, 7 - the tool driving hole

5. raising the tool and sliding the tool out from the end effector which stays inside the socket fixed by the clamp spring; 
6. rotation of the magazine disc in order to place the desired end effector under the tool;

7. lowering the tool and sliding the tool wrist into the end effector;

8. closing the tool jaws which results in:

a) blocking the new end effector in the tool's cluster, and also

b) unlocking the end effector in the socket by sliding the arms of the clamp spring out of dents in jaw (1);

9. moving the end effector out of the socket;

10. rotating the magazine in order to place the hole under the tool;

11. sliding the tool inside a patient's body.
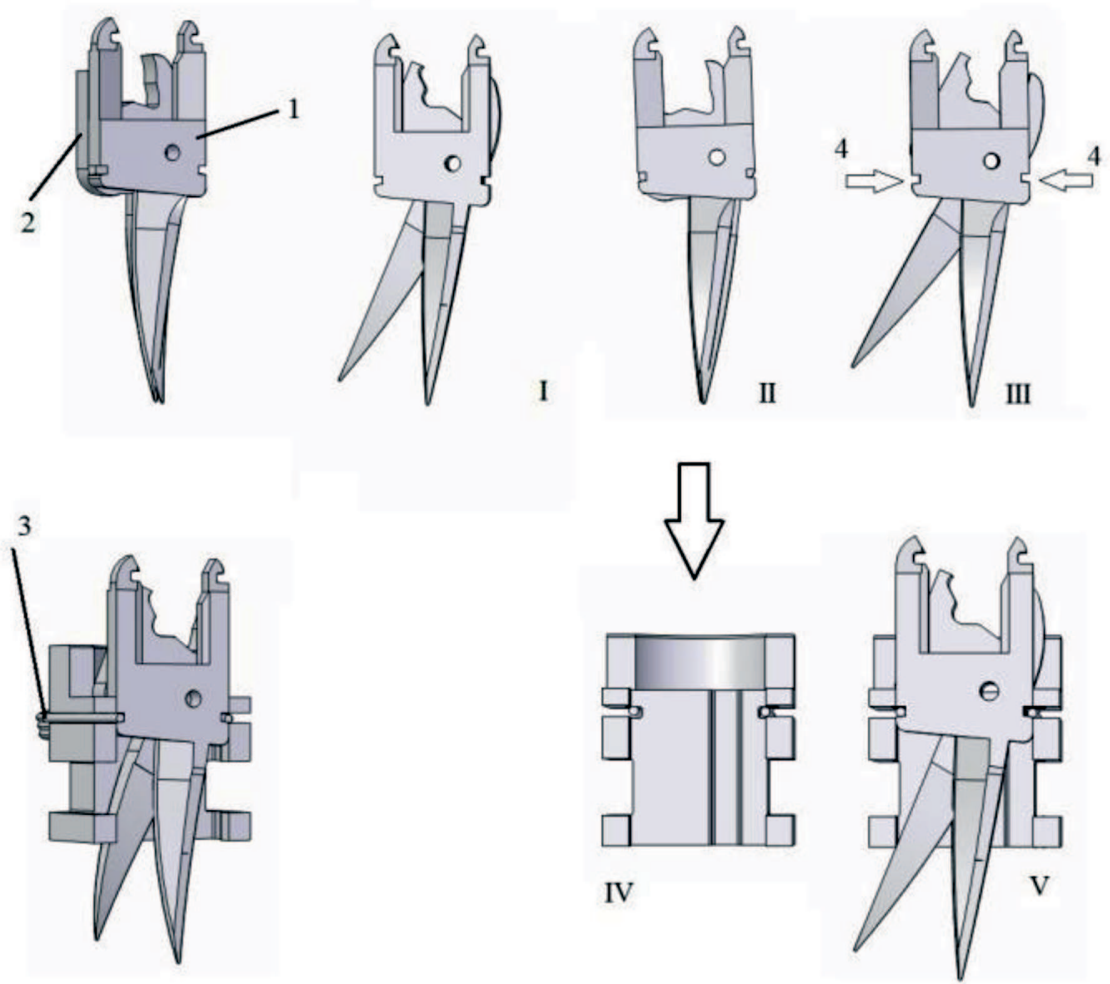

Fig. 5. Stages of tool changing. Draft of the end effectors changing mechanism. 1 - jaw fixed with tool wrist, 2 - jaw propulsion, 3 - clamp spring, 4 - clamp spring dents [15]

The presented construction of the tool system with an automated end effectors magazine shows its advantage over the currently used solutions. The main advantage is the reduction of tool changing time to 10 seconds by using automated end effectors interchanging process, which shortens the whole surgery time. Due to this fact, the operating staff don't need an operation assistant any more. 


\section{Ergonomics of operating with of RobIn Heart}

One of the most important issues for telemanipulators is the intuitive control system [12]. This is particularly important in the case of surgical telemanipulators, in which the camera position is variable and it cannot be predicted at the stage of software development. For this purpose, a new algorithm was developed and implemented in the control system. It copies the increments of position $A_{\varepsilon} d_{m}^{z}$ and orientation $R_{m}^{z}$ measured in relation to the monitor coordinate system onto the robot movement $\Delta d_{k}^{r}$ and the tool orientation $R_{k}^{r}$ which are measured in relation to the camera coordinates (Fig. 6). It is necessary to know the camera and monitor place, but due to the fact that the position is copied incrementally all the time, only the rotation matrixes $R_{o}^{m}$ and $R_{p}^{k}$ are required for the calculation (where $R_{o}^{m}$ describe rotation of monitor coordinates system $(\mathrm{m})$ in relation to base coordinate system of master (o) and $R_{p}^{k}$ describe rotation of camera coordinates (k) in relation to base coordinate system of robot (p)). These matrices determine the angular position of the monitor relative to the base frame of the master manipulator and the angular position of the camera relative to the base frame of the robot. It may be noted that:

$$
\begin{gathered}
\Delta d_{m}^{z}=R_{m}^{o} \Delta d_{o}^{z} \\
R_{m}^{z}=R_{m}^{o} R_{o}^{z}
\end{gathered}
$$

and

$$
\begin{gathered}
\Delta d_{k}^{r}=R_{k}^{p} \Delta d_{p}^{r} \\
R_{k}^{r}=R_{k}^{p} R_{p}^{r}
\end{gathered}
$$

Using the approved procedure, $\Delta d_{k}^{r}=\Delta d_{m}^{z}$ and $R_{k i}^{r}=R_{m i}^{z}$ procedures of movements combining relatively the established coordinates system, the formula for the position and orientation may be determined as:

$$
\begin{aligned}
& R_{p i}^{r}=\left(R_{k}^{p}\right)^{-1} R_{m}^{o} R_{o i}^{z}=R_{p}^{k} R_{m}^{o} R_{o i}^{z} \\
& d_{p i}^{r}=R_{p}^{k} R_{m}^{o}\left(d_{o i}^{z}-d_{o i-1}^{z}\right)+d_{p i-1}^{r}
\end{aligned}
$$

In order to determine the rotation matrices $R_{o}^{m}$ and $R_{p}^{k}$, a new procedure of acquisition of monitor and camera position has been developed. Details of control ergonomics were presented in [7]. 

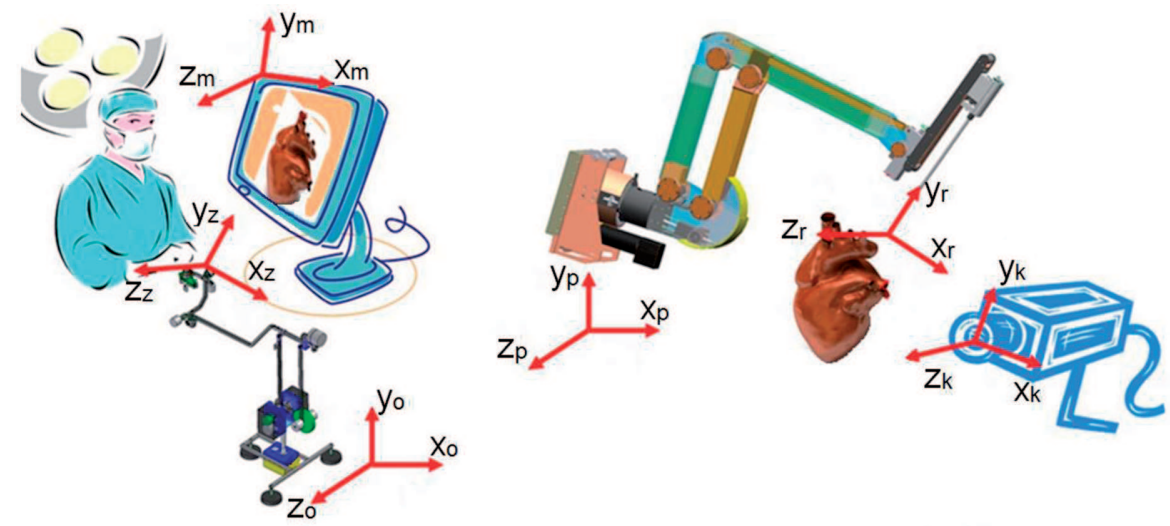

Fig. 6. Coordinates systems associated with each component of RobIn Heart telemanipulator where: $\mathrm{x}_{o} \mathrm{y}_{o} \mathrm{z}_{o}$ - base coordinate system of master manipulator, $\mathrm{x}_{m} \mathrm{y}_{m} \mathrm{z}_{m}$ - coordinate system of monitor, $\mathrm{x}_{z} \mathrm{y}_{z} \mathrm{z}_{z}$ - coordinate system of master's handle, $\mathrm{x}_{p} \mathrm{y}_{p} \mathrm{z}_{p}$ - base coordinate system of robot,

$\mathrm{x}_{r} \mathrm{y}_{r} \mathrm{z}_{r}$ - coordinate system of robot's tool (TCP), $\mathrm{x}_{k} \mathrm{y}_{k} \mathrm{z}_{k}$ - coordinate system of camera

\section{Inverse kinematics task}

The second problem relevant to control algorithms is determination of joint variables on the basis of the commanded position of the robot $d_{p}^{r}$ and orientation $R_{p}^{r}$ measured relation to the robot base frame.

In the paper [8], a simplified model of the RobIn Heart has been used to describe a method of solving inverse task of kinematics. In that model, the assumption that the robot has 6 DOF has been made. That simplification was possible due to the fact that the $5^{\text {th }}$ and $6^{\text {th }}$ joint axis are parallel and close to each other. This paper shows a full model of kinematics of the RobIn Heart with all 7 DOF.

Fig. 7 shows the model of the robot. Coordinate systems were chosen according to the Denavit-Hartenberg's convention. There are two additional transform matrixes: $T_{0}^{1}$ and $T_{8}^{9}$, so the Z-axis of the $O_{0} x_{0} y_{0} z_{0}$ coordinate system would be vertical and the Z-axis of the $O_{9} x_{9} y_{9} z_{9}$ coordinate system would be coaxial with the tool. Joint parameters are presented in Table 1.

In case of solving the direct kinematics task, one has to calculate transformation between the coordinate system associated with the tool, and the base of the robot. Equation (7) describes the direct kinematic task involving the parameters from Table 1 .

$$
T_{0}^{9}=T_{0}^{1} T_{1}^{2} T_{2}^{3} T_{3}^{4} T_{4}^{5} T_{5}^{6} T_{6}^{7} T_{7}^{8} T_{8}^{9}
$$

Solving the inverse kinematics task consists of deriving the joint variables $\theta_{1}, \theta_{2}, \theta_{3}, d_{4}, \theta_{5}, \theta_{7}$ basing on the assigned position and orientation of the effector 
Table 1.

The parameters of RobIn Heart's model

\begin{tabular}{|c|c|c|c|c|}
\hline Joint & $a_{i}$ & $\alpha_{i}$ & $d_{i}$ & $\theta_{i}$ \\
\hline$T_{0}^{1}$ & 0 & $\pi / 2$ & 0 & 0 \\
\hline$T_{1}^{2}$ & 0 & $\pi / 2$ & 0 & $\theta_{1}+\pi / 2$ \\
\hline$T_{2}^{3}$ & 0 & $\pi / 2$ & 0 & $\theta_{2}+\pi / 2$ \\
\hline$T_{3}^{4}$ & 0 & 0 & 0 & $\theta_{3}$ \\
\hline$T_{4}^{5}$ & 0 & $\pi / 2$ & $d_{4}$ & $\pi$ \\
\hline$T_{5}^{6}$ & $a_{5}$ & 0 & 0 & $\theta_{5}+\pi / 2$ \\
\hline$T_{6}^{7}$ & $a_{6}$ & $\pi / 2$ & 0 & $\theta_{6}=\theta_{5}$ \\
\hline$T_{7}^{8}$ & $a_{7}$ & 0 & 0 & $\theta_{7}$ \\
\hline$T_{8}^{9}$ & 0 & $\pi / 2$ & 0 & $\pi / 2$ \\
\hline
\end{tabular}
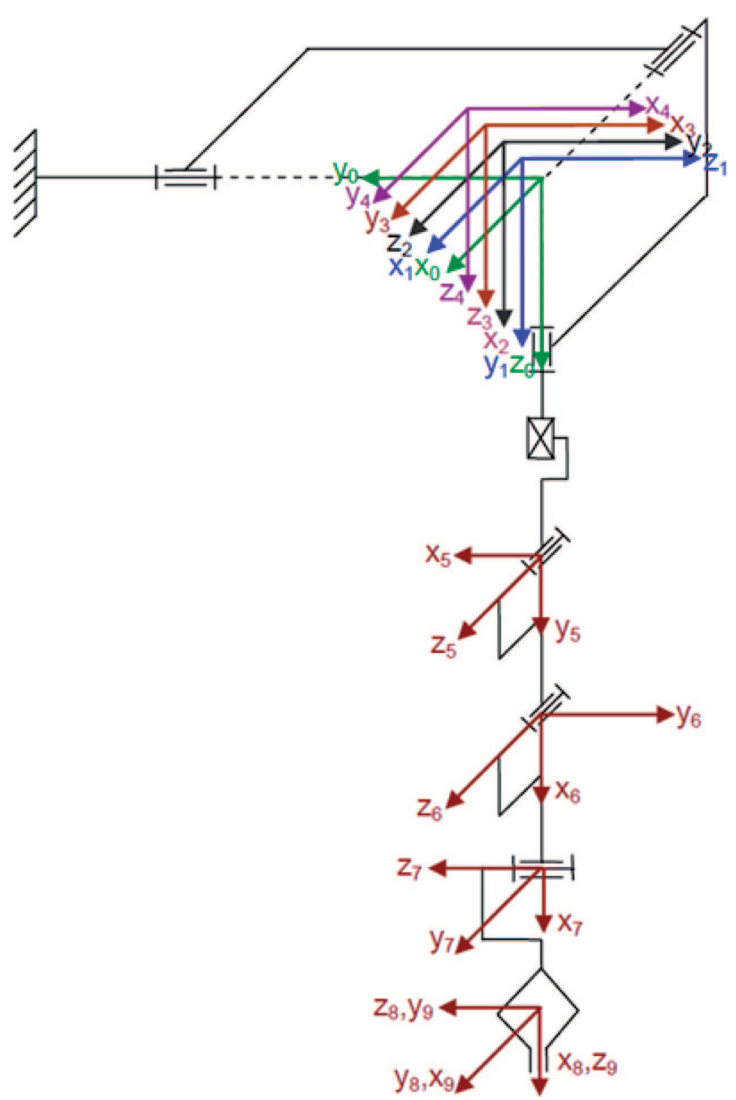

Fig. 7. The model of the RobIn Heart robot 
measured in the base coordinate system or in another known transform matrix $T_{0}^{9}$. Joints $\theta_{5}$ and $\theta_{6}$ are coupled by means of tendons, so they have the same value. These joints are driven by one motor. As it can be noticed from equation (7), solving the inverse kinematics is a task of greater difficulty than direct kinematics. If the robot has a spherical wrist (three axis of wrist's joints crossing in one point), such a task could be simplified by dividing it into two tasks. The first task describes inverse kinematics of the position of the wrist, and the second describes the orientation of the wrist.

The RobIn Heart is the spherical manipulator (axis of $1^{s t}, 2^{\text {nd }}$ and $3^{\text {rd }}$ joints crossing in one point). By changing the roles of the effector and base, such a feature can be utilized. Equation (8) shows the matrix transforming the new "base" to the new "effector".

$$
\begin{gathered}
T_{9}^{0}=T_{9}^{8} T_{8}^{7} T_{7}^{6} T_{6}^{5} T_{5}^{4} T_{4}^{3} T_{3}^{2} T_{2}^{1} T_{1}^{0} \\
T_{9}^{0}=\left(T_{0}^{9}\right)^{-1}
\end{gathered}
$$

In order to derive the joint variables basing on the assigned position and orientation of the tool, one should derive the $T_{0}^{9}$ transform matrix from $O_{9} x_{9} y_{9} z_{9}$ coordinate system to $O_{0} x_{0} y_{0} z_{0}$ coordinate system (7). The next step is to derive the $T_{9}^{0}$ transform matrix from $O_{0} x_{0} y_{0} z_{0}$ coordinate system to $O_{9} x_{9} y_{9} z_{9}$ coordinate system which is the inversion of $T_{0}^{9}(9)$. The $O_{0} x_{0} y_{0} z_{0}$ coordinate system is rotated relative to the $O_{4} x_{4} y_{4} z_{4}$ by $\theta_{1}, \theta_{2}, \theta_{3}$ angles. Position of the $O_{0} x_{0} y_{0} z_{0}$ is independent from $\theta_{1}, \theta_{2}, \theta_{3}$ coordinates. Calculation of $T_{9}^{4}$ matrix describing position of this point by using only $d_{4}, \theta_{5}, \theta_{7}$ coordinates is possible (10).

$$
T_{9}^{4}=T_{9}^{8} T_{8}^{7} T_{7}^{6} T_{6}^{5} T_{5}^{4}=\left[\begin{array}{cccc}
r_{11} & r_{12} & r_{13} & d_{x} \\
r_{21} & r_{22} & r_{23} & d_{y} \\
r_{31} & r_{32} & r_{33} & d_{z} \\
0 & 0 & 0 & 1
\end{array}\right]
$$

By performing a simple transformation, one can obtain the position of the $O_{4} x_{4} y_{4} z_{4}$ coordinate system as an equations (11).

$$
\begin{gathered}
d_{x}=2 d_{4} c_{5}^{2} s_{7}+a_{5} c_{5} s_{7}-d_{4} s_{7}+a_{6} s_{7} \\
d_{y}=-2 d_{4} c_{5} s_{5}-a_{5} s_{5} \\
d_{z}=-2 d_{4} c_{5}^{2} c_{7}-a_{5} c_{5} c_{7}+d_{4} c_{7}-a_{6} c_{7}-a_{7}
\end{gathered}
$$

Unknown parameters $d_{4}, \theta_{5}, \theta_{7}$ can be computed as follows:

$$
\theta_{7}=\arctan \left(\frac{-d_{x}}{d_{z}+a_{7}}\right)
$$


Deriving $\theta_{5}$ requires solving a non-linear trigonometric equation. This task is of great difficulty. Instead, one can approximate $\theta_{5}$ angle with following script 13.

$$
\begin{aligned}
& \text { Script } \\
& \text { 10. } a=d_{x} /\left(\sin \left(\theta_{7}\right)-a_{6}\right) ; \\
& \text { 20. } \theta_{5}=-\operatorname{atan} 2\left(d_{y}, a\right) / 2 ; \\
& \text { 30. for }(i=0 ; i<3 ; i++) \\
& \text { 40. } \theta_{5}=-\arctan 2\left(d_{y}+a_{5} \sin \left(\theta_{5}\right), a-a_{5} \cos \left(\theta_{5}\right)\right) / 2 \text {; } \\
& \qquad d_{4}=\frac{-d_{y}-a_{5} \sin \left(\theta_{5}\right)}{2 \cos \left(\theta_{5}\right) \sin \left(\theta_{5}\right)}
\end{aligned}
$$

After solving equations $(12,13,14)$ the matrix $T_{9}^{4}$ is known. One can compute wrist's joints variables. The matrix $R_{9}^{0}$ of base orientation in the wrist's coordinate system is known.

$$
R_{9}^{0}=R_{9}^{4} R_{4}^{0}
$$

The $R_{9}^{4}$ orientation matrix is a part of the $T_{9}^{4}$ transform matrix. With equation (15), one can derive base orientation matrix relation to $O_{4} x_{4} y_{4} z_{4}$ coordinate system as follows:

$$
R_{4}^{0}=\left(R_{9}^{4}\right)^{-1} R=\left(R_{9}^{4}\right)^{T} R
$$

On the other hand, as a result of multiplication of the transform matrixes $T_{4}^{3}, T_{3}^{2}, T_{2}^{1}, T_{1}^{0}$ from $O_{0} x_{0} y_{0} z_{0}$ coordinate system related to base to $O_{4} x_{4} y_{4} z_{4}$ coordinate system the $R_{4}^{0}$ orientation matrix can be computed.

$R_{4}^{0}=\left[\begin{array}{lll}\sin \left(\theta_{1}\right) \sin \left(\theta_{2}\right) \cos \left(\theta_{3}\right)+\cos \left(\theta_{1}\right) \sin \left(\theta_{3}\right) & -\cos \left(\theta_{2}\right) \cos \left(\theta_{3}\right) & -\cos \left(\theta_{1}\right) \sin \left(\theta_{2}\right) \cos \left(\theta_{3}\right)+\sin \left(\theta_{1}\right) \sin \left(\theta_{3}\right) \\ -\sin \left(\theta_{1}\right) \sin \left(\theta_{2}\right) \sin \left(\theta_{3}\right)+\cos \left(\theta_{1}\right) \cos \left(\theta_{3}\right) & \cos \left(\theta_{2}\right) \sin \left(\theta_{3}\right) & \cos \left(\theta_{1}\right) \sin \left(\theta_{2}\right) \sin \left(\theta_{3}\right)+\sin \left(\theta_{1}\right) \cos \left(\theta_{3}\right) \\ -\sin \left(\theta_{1}\right) \cos \left(\theta_{2}\right) & -\sin \left(\theta_{2}\right) & \cos \left(\theta_{1}\right) \cos \left(\theta_{2}\right)\end{array}\right]$

Comparing both matrixes, one can compute unknown parameters as follows:

$$
\begin{gathered}
\theta_{2}=\arcsin \left(\left(\sin \left(\theta_{7}\right) r_{12}+\cos \left(\theta_{7}\right) r_{32}\right)\left(2 \cos \left(\theta_{5}\right)^{2}-1\right)+2 \cos \left(\theta_{5}\right) \sin \left(\theta_{5}\right) r_{22}\right) \\
\theta_{1}=\arccos \left(\frac{\left(\cos \left(\theta_{7}\right) \cdot r_{33}-\sin \left(\theta_{7}\right) \cdot r_{13}\right) \cdot\left(2 \cos \left(\theta_{5}\right)^{2}-1\right)+2 \cos \left(\theta_{5}\right) \sin \left(\theta_{5}\right) \cdot r_{23}}{\cos \left(\theta_{2}\right)}\right) \\
\theta_{3}=\arcsin \left(\frac{\cos \left(\theta_{7}\right) \cdot r_{12}+\sin \left(\theta_{7}\right) \cdot r_{32}}{\cos \left(\theta_{2}\right)}\right)
\end{gathered}
$$


The formulas presented above have been used in the control system of the RobIn Heart robot. The presented kinematics gives, the robot its singularities. The example of the singularity passing test is presented in Fig. 8 and 9. Fig. 8 shows the input parameters: position $(\mathrm{X}, \mathrm{Y}, \mathrm{Z})$ and orientation (Euler angles: precession, nutation and rotation) by the dotted line. In Fig. 9 the dotted lines presents changes of joint variables values $\theta_{1}, \theta_{2}, \theta_{3}, d_{4}, \theta_{5}, \theta_{7}$ calculated directly from the equations above. The discontinuity of the joint variables $\theta_{5}$ and $\theta_{7}$ can be seen. The respective positions in joint space for the adjacent positions in the task space are completely distant (Fig. 10).

It has led to developing the special correction function that allows passing through singularity without rapid change of joint variables.

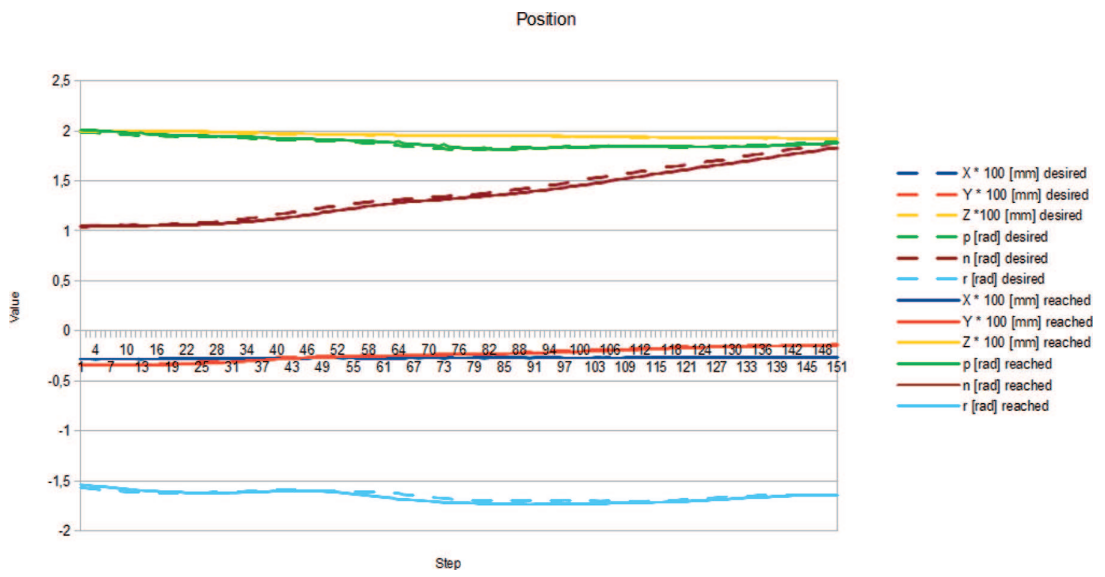

Fig. 8. Desired (a dotted line) and reached as the result of the safety function (a continuous line) position, while passing a singularity

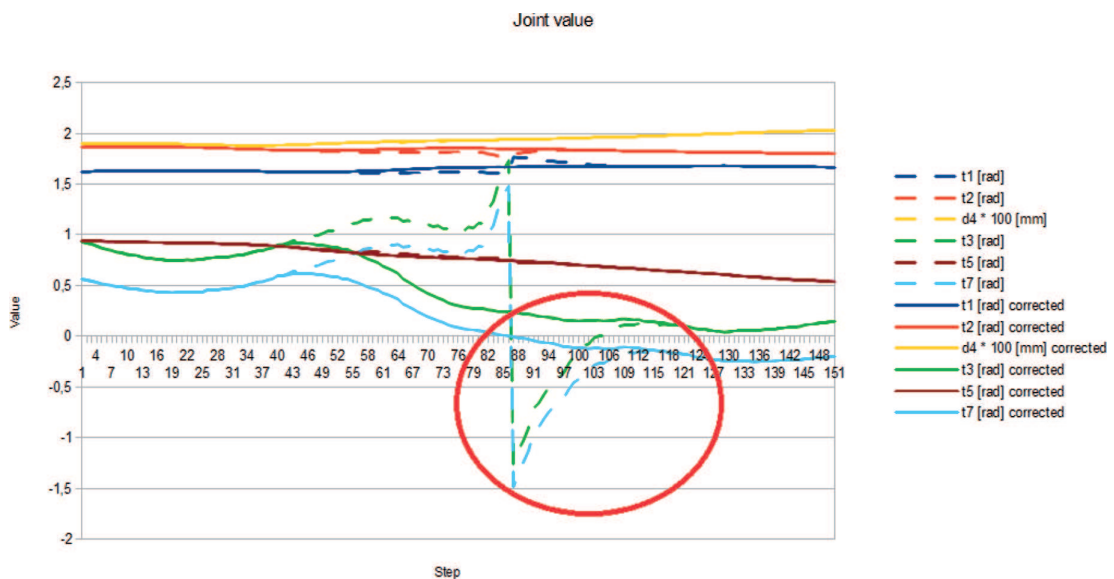

Fig. 9. Desired (a dotted line) and reached as the result of the safety function (a continuous line) joint variables, while passing a singularity 


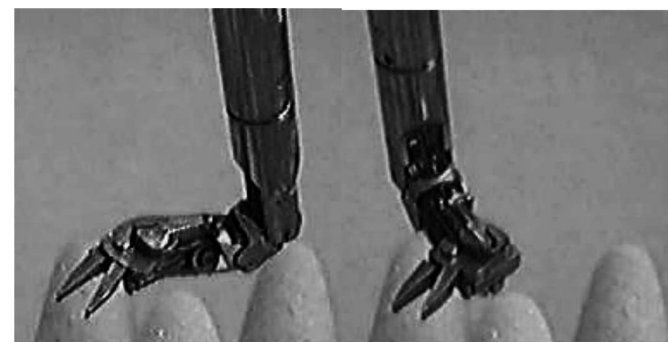

Fig. 10. Rapid change of joint variables for close positions of the tool

It may be noted that, when the expression $\left(d_{z}+a_{7}\right)$ changes its sign, a discontinuity in equation (12) and a whole of the solution appears. It was necessary to find a method for determining the joint variables that would be free of singularities. A hint to finding a suitable solution was the statement that, when a manipulator has less than $6 \mathrm{DOF}$, there needs to be a projection of the command position to the area of available positions. In such a case, it appears when $-d_{z}=a_{7}$ and the projection can be noted as $d_{x k o r}=0$ However, it should be noted that, in order to meet the requirements for real control systems, the solution of the inverse kinematics should be differentiable and have continuous first derivative.

In this situation, the proposed projection includes a range $r$ of parameter $d_{z}$. As a projecting function the cosine function has been selected - because of its continuity:

$$
\text { for }\left|d_{z}+a_{7}\right|<r \quad d_{x k o r}=d_{x}\left(0.5-0.5 \cos \left(\frac{\pi\left(d_{z}+a_{7}\right)}{r}\right)\right)
$$

Such a solution fulfills all the aforementioned requirements for differentiability and continuity. It means that:

- displacement of each joint of the manipulator has to be a continuous function with respect to time - it is a necessary (but not sufficient) condition for differentiability;

- displacement of each joint of the manipulator has to be a differentiable function with respect to time - it means that it has to be possible to evaluate joint velocities;

- joint velocities have to be continuous functions - if this condition is not fulfilled, it is not possible to generate required moments by drive units.

All the sentences mentioned above may be simplified to a sentence that joint velocities have to exist and be continuous. This issue is a result of the fact that moments in the joints of the manipulator are the function of displacements, velocities and accelerations according to the equation:

$$
B(q) \ddot{q}+c(q, \dot{q})+h(q)+r(q, \dot{q})=\tau
$$


where: $\mathrm{q}$ - vector of joint variables, $\mathrm{B}$ - matrix of inertia, $\mathrm{c}$ - vector of centrifugal and Coriolis forces and moments, $\mathrm{h}$ - vector of gravity and elasticity forces and moments, $\mathrm{r}$ - vector of friction forces and torques, $\tau$ - vector of drive forces and moments.

Besides, inverse kinematics solutions have to be possible to perform by the manipulator with respect to different constraints - mechanical constraints of the joint movement range, program constraints of the joint maximum velocity, maximum force or moment constraints due to the drive units characteristics.

Obtaining the continuous function of forces and moments in the manipulator's joints is necessary due to drive devices features. The continuity of the above function is a result of the continuity of displacement and velocity. Sometimes it is also necessary to obtain the continuous second derivative (acceleration) and third derivative (jerk).

Another problem of inverse kinematics is singularities. They are the configurations where performing a small move of the effector requires infinite joint velocities values.

If forward kinematics is formulated as [13]:

$$
y_{d}(t)=k\left(q_{d}(t)\right)
$$

Inverse velocity kinematics may be noted as [13]:

$$
\dot{q}_{d}(t)=\left(\frac{\partial k}{\partial q}\left(q_{d}(t)\right)\right)^{-1} \dot{y}_{d}(t)
$$

The expression in the brackets is the Jacobian matrix of the manipulator. It is impossible to inverse this matrix when being in a singular position because its determinant is equal to zero and some of joint velocities may tend to infinity.

A solution for avoiding this problem is counting joint velocities in some neighbourhood of singular position by a different algorithm.

The proposed solution makes it possible to pass through the singularity area with reducing joint velocities values. It is assumed that command values which are read from real master manipulator met the requirements for continuity and differentiability including their derivatives.

Below it will be shown that when the function is expressed as:

$$
d_{x k o r}= \begin{cases}d_{x}\left(0.5-0.5 \cos \left(\frac{\pi\left(d_{z}+a_{7}\right)}{r}\right)\right) & \text { for }\left|d_{z}+a_{7}\right|<r \\ d_{x} & \text { for }\left|d_{z}+a_{7}\right| \geq r\end{cases}
$$

it is continuous and differentiable in all its domain (Fig 11). 
The continuity in the piecewise point means that for $\left|d_{z}+a_{7}\right|=r$ condition $d_{x k o r}=d_{x}$ is fulfilled. Differentiability for $\left|d_{z}+a_{7}\right|<r$ is fulfilled because cosine is $C^{\infty}$ function.

The only point where this function may not be differentiable is when the function enters and leaves the area of approximate solution where $\left|d_{z}+a_{7}\right|=r$. The necessary condition for differentiability of this function is its continuity, the condition which is fulfilled. The sufficient conditions for differentiability of this function is the existence of left and right side derivatives and equality of these derivatives.

It will be proved that the chosen mapping function is continuous and differentiable for $\left|d_{z}+a_{7}\right|=r$.

For $\left|d_{z}+a_{7}\right|=r$ occurs:

$$
\begin{aligned}
\lim _{\left|d_{z}+a_{7}\right| \rightarrow r^{-}} d_{x k o r} & =\lim _{\left|d_{z}+a_{7}\right| \rightarrow r^{-}} d_{x}\left(0.5-0.5 \cos \left(\frac{\pi\left(d_{z}+a_{7}\right)}{r}\right)\right)= \\
& =d_{x}\left(0.5-0.5 \cos \left(\frac{\pi r}{r}\right)\right)=d_{x} \\
& \lim _{\left|d_{z}+a_{7}\right| \rightarrow r^{+}} d_{x k o r}=\lim _{\left|d_{z}+a_{7}\right| \rightarrow r^{-}} d_{x}=d_{x}
\end{aligned}
$$

The left and right side function limits are equal, so the function is continuous for $\left|d_{z}+a_{7}\right|=r$

Now the left and right side $d_{x k o r}$ function limits will be evaluated for $\left|d_{z}+a_{7}\right|=r$ :

$$
\begin{gathered}
d_{x k o r}^{\prime}{ }^{+}=0.5 d_{x} \sin \left(\frac{\pi\left(d_{z}+a_{7}\right)}{r}\right) \frac{\pi}{r}+d_{x}^{\prime}\left(0.5-0.5 \cos \left(\frac{\pi\left(d_{z}+a_{7}\right)}{r}\right)\right) \\
d_{x k o r}^{\prime}{ }^{-}=d_{x}^{\prime}
\end{gathered}
$$

For $\left|d_{z}+a_{7}\right|=r$ it may be noted that:

$$
\begin{gathered}
d_{x k o r}^{\prime}{ }^{+}=0.5 d_{x} \sin \left(\frac{\pi r}{r}\right) \frac{\pi}{r}+d_{x}^{\prime}\left(0.5-0.5 \cos \left(\frac{\pi r}{r}\right)\right)=d_{x}^{\prime} \\
d_{x k o r}^{\prime}{ }^{-}=d_{x}^{\prime}
\end{gathered}
$$

The equality of left and right side derivatives implies existing of $d_{x k o r}^{\prime}$ derivative for $\left|d_{z}+a_{7}\right|=r$.

Therefore, the mapping function is differentiable.

For practical reasons, it was proved that the projection should not change the position of the robot, but only the orientation. To do this, it is necessary to modify $d_{y}$ parameter to fulfill the equation:

$$
d_{x k o r}^{2}+d_{y k o r}^{2}=d_{x}^{2}+d_{y}^{2}
$$




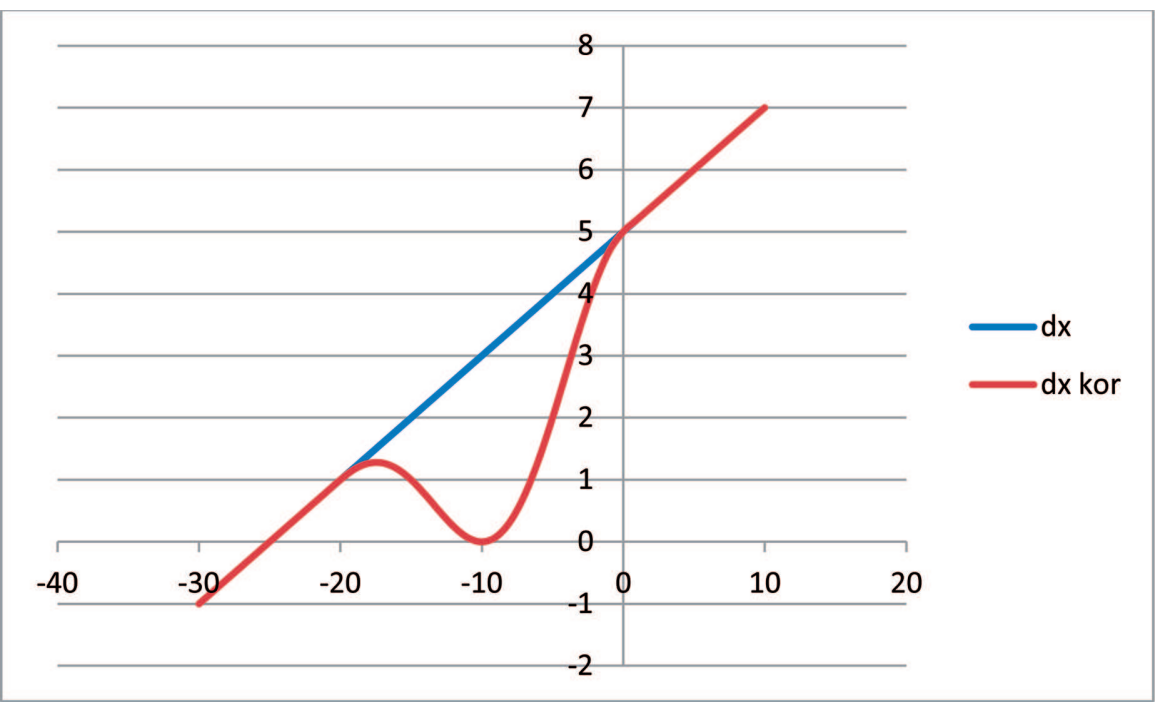

Fig. 11. Mapping function

Thanks to the presented algorithm, it is possible to pass through a discontinuity area. The only disadvantage is a slight temporary change of tool orientation.

The example of the algorithm functioning is presented in Fig. 8 and Fig. 9 as a continuous line. Fig. 8 shows the input parameters: position $(\mathrm{X}, \mathrm{Y}, \mathrm{Z})$ and orientation (Euler angles: precession, nutation and rotation) as well as output position and orientation. As it can be seen, there is no significant difference between input and output parameters. The output is an activity of the correction function.

Fig. 9 presents changes of joint variables values $\theta_{1}, \theta_{2}, \theta_{3}, d_{4}, \theta_{5}, \theta_{7}$. In the Fig. 9, the area of difference caused by safety function has been marked.

\section{Conclusions and acknowledgment}

Although the research on RobIn Heart robot started in 2000 and basic construction elements were designed in 2003, this research area is still open and there is a very wide scope for further improvements. This applies to both the mechanical design and control algorithms or master manipulators.

This work was made in grants 2011/01/B/ST7/04011 and 2012/05/N/ST8/02262 from National Science Centre. 


\section{REFERENCES}

[1] Hagn U. i inni: DLR MiroSurge - towards versatility in surgical robotics. September, 24-26, 2008, pp. 143-146.

[2] Frącczak Ł.: "Mathematical Model of the Servo Drive with Friction Wheels. Simulations and Real Object Examination Results" Solid State Phenomena 2013 (Volume 198), Mechatronic Systems and Materials IV, pp 15-20.

[3] Nawrat Z. i inni: Robin Heart 2003 - Present state of polish telemanipulator project dedicated for cardiac surgery. The International Journal of Artificial Organs. Vol. 26, no. 12, 2003, pp. 1115-1119.

[4] Nawrat Z., Kostka P., Podsędkowski L., Dybka W., Kandora A.: "Robin Heart Vision telemanipulator of endovision path" - in Polish "Telemanipulator toru endowizyjnego Robin Heart Vision". Warszawa. PAR - Pomiary Automatyka Robotyka. Miesięcznik NaukowoTechniczny, 2/2007 str. 1-9.

[5] Nawrat Z., Kostka P., Dybka W., Rohr K., Podsędkowski L., Śliwka J., Cichoń R., Zembala M., Religa G.: "The Robin Heart surgical robot system in vivo experiments- report" The International Journal of Artificial Organs / Vol. 32 / no. 7, 2009.

[6] Podsędkowski L., Żak P.: "Tests on Cardiosurgical Robot RobIn Heart 3" Lecture Notes in Control and Information Sciences, Springer Verlag, Volume 396/2009.

[7] Podsędkowski L., Wróblewski P., Zawierucha M.: "Telemanipulator Control with Varying Camera Position" Solid State Phenomena Vol. 198 (2013) pp 275-280.

[8] Podsędkowski L.: "Forward And Inverse Kinematics of the Cardio-Surgical Robot With NonCoincident Axis of the Wrist" SIROCCO 2003, pp. 525-530.

[9] Wróblewska A.: "Methods of the force measurement for robotic surgical tools" konferencja Workshop On Robot Motion And Control RoMoCo/05 23-25 June 2005r. Dymaczewo.

[10] Kobierska A.: "Force Sensor for Laparoscopic Tool of RobIn Heart Robot" Solid State Phenomena Vol. 199 (2013) pp 309-314.

[11] Zawiasa P.: "New tooltips for RobIn Heart robot" in Polish "Nowe końcówki narzędziowe do robota RobIn Heart" MEDICAL ROBOTS, Zabrze 2007.

[12] Żak P.: "Using 9-axis Sensor for Precise Cardiosurgical Robot Master Angular Position Determination" Solid State Phenomena Vol. 199 (2013) pp 356-361.

[13] Tchoń K., Muszyński R.: "A normal form solution to the singular inverse kinematic problem for robotic manipulators: the quadratic case", IEEE International Conference of Robotics and Automation, 1998.

[14] Kobierska A., Podsędkowski L., Wróblewski P., Zawiasa P.: "New mechanical solutions in Robin Heart robot tooling system" in Polish "Nowe mechaniczne rozwiązania systemu narzędziowego robota RobIn Heart”, Mechanik - Miesięcznik naukowo-techniczny, 12/2012.

[15] Brzezowski A.: "The automated endeffectors magazine", in Polish "Zautomatyzowany magazyn narzędzi robota medycznego” Master’s Thesis, IOiTBM Politechnika Łódzka, 2012.

[16] Mazur A., Podsędkowski L., Szymański A., Zawierucha M.: "Compliance force control for Polish cardiosurgical manipulator RobIn Heart Heart" ROMOCO 2013.

[17] [Online] Intuitive Surgical Ltd. www.intuitivesurgical.com

[18] [Online] German Aerospace Center, Institute of Robotics and Mechatronics. http://www.dlr.de/rm/en/desktopdefault.aspx/tabid-3795/ 
Wybrane aspekty sterowania robota RobIn Heart

\section{Streszczenie}

Problematyka robotów medycznych jest od 12 lat rozwijana w Instytucie Obrabiarek i TBM Politechniki Łódzkiej. W ciągu ostatnich dwóch lat prace badawcze koncentrowały się na miniaturyzacji narzędzi chirurgicznych, procedurach automatycznej wymiany tych narzędzi z wykorzystaniem zaprojektowanego do tego celu magazynu końcówek narzędziowych, wyposażeniu robota w zmysł dotyku oraz na opracowaniu oprogramowania, które w ergonomiczny i intuicyjny sposób pozwoli sterować robotem z wykorzystaniem wszystkich jego możliwości. W zakresie kontroli telemanipulatora silny nacisk został położony na intuicyjny sposób sterowania, który jest trudny do zrealizowania, gdyż układy współrzędnych obserwatora i narzędzia mogą być w różnych położeniach. To skłoniło zespół z PŁ do opracowania nowego algorytmu sterowania, który kopiuje zmiany położenia i orientację mierzone względem układu współrzędnych monitora na ruch robota i orientację narzędzia mierzone względem układu współrzędnych kamery. W metodzie tej wykorzystano rozwiązanie zadania odwrotnego z uwzględnieniem nieciągłości rozwiązania. W celu uniknięcia jej została wykorzystana funkcja kosinus, dzięki czemu uzyskano płynne przejście przez strefę nieciągłości. 